\title{
Neoplastic Polyp
}

National Cancer Institute

\section{Source}

National Cancer Institute. Neoplastic Polyp. NCI Thesaurus. Code C7068.

A term that includes all polypoid growth from the inner lining of the mucous membrane. 